\title{
Field survey and spatial distribution of Tropical Neogastropod, Thais spp., along Malaysian Coastal Area.
}

\begin{abstract}
Tropical marine neogastropod has been proposed to be a bioindicator for marine pollution. A field survey was conducted to determine the spatial distribution of Thais spp. along the Malaysian coastline. The density of Thais spp. in each area was calculated using the timed search method. More than 40 percent of the total surveyed sites were identified to have Thais spp. present. On average, the abundance rating for Thais spp. in Malaysia was a common species with density (D) of about 720 individuals/hour/ person. About 50 percent of Thais spp. habitats can be categorised as a frequent-occasional abundance rating. This study found that Thais spp. prefer to occupy a sandy or mixed sedimentary beach with boulder(s) either naturally existing or a man-made wave barrier along reclaimed beaches. This study found that a suitable habitat for Thais spp. must consist of prey items being present, exposure to the open sea and strong waves, and must be located within tidal activities. Limited human activities around their habitat do not have direct effects on Thais spp. presence. However, further investigations on the implications of human activities in the habitat of Thais spp. along Malaysian coastal areas should be conducted.
\end{abstract}

Keyword: Tropical neogastropod; Thais spp.; Spatial distribution; Density; Malaysia. 